\title{
A STUDIES OF LANNA COMMUNITY - BASED ANALYSIS MANAGEMENT SKILLS TO HANDS-ON GRADUATES IDENTITY FOR COMMUNITY, CHIANG MAI ,THAILAND
}

\author{
Lamai Passadee ${ }^{1}$, Charin MangKhang ${ }^{2}$, Sawaen Saenbutr ${ }^{3}$ and Thongchai Phuwanatwichit ${ }^{4}$ \\ 1,2 Faculty of Education, Chiang Mai University, Chiang Mai 50200, Thailand \\ ${ }^{3,4}$ Faculty of Humanities, Chiang Mai University, Chiang Mai 50200, Thailand
}

DOI: 10.46609/IJSSER.2021.v06i01.003 URL: https://doi.org/10.46609/IJSSER.2021.v06i01.003

\section{ABSTRACT}

The objective of this article is to generate the conceptual framework of Lanna community-based analysis management skills to hands-on graduates' identity for the community. This is paperbased research which integrates the information from the ideas, theories and research project that related to analysis management of the Lanna community. As a result, there are three main skills for graduates' identity to generate the learning process through Lanna Community Based Analysis which includes 1) Technical skills 2) Human skills and 3) Conceptual Skills.

The outcome of Lanna community-based analysis management skills to hands-on graduates identity for the community of students from the Rajamangala University of Technology Lanna is that the students should be encouraged in management skills which include technical skills, human skills, and conceptual skills. According to the concept of Robert L Katz (1955), we adopted the student's development process by using Lanna Community Based Analysis. Following ideas, we generate the process of development to correlate with Lanna Community Based Analysis. Firstly, analyzing the Lanna community. Secondly, learning from the Lanna Community Based Analysis. Thirdly, reviewing the Lanna community. Next, conceptualize the Lanna community and lastly, applying the ideas according to the experience in the Lanna community. The reflection from students was that students can learn from real Lanna Community Based Analysis. They can show their planning, management, and hands-on skills. Moreover, they also learn the process of solving the problems, enjoying outside classroom learning and satisfying the process of Lanna community-based analysis management skills.

Keywords: Lanna Community Based Analysis, Management skills,Hands-On Graduates Identity For Community 


\section{International Journal of Social Science and Economic Research}

ISSN: $2455-8834$

Volume:06, Issue:01 "January 2021"

\section{Introduction}

The core component in social development is human. Thus, the initial step for developing the country is the development of humans into perfect human-being because human resources are the most important resource for good social development. In Thailand, the National Education Act of 1999, as amended (No. 2) of 2002 and the National Education Plan (revised version) of 2012-2019 gives importance to the educational system which is a core value to develop humanity. The educational system at the university level is an important key in managing education that emphasizes the desirable characteristics of students under university and being able to live with other people in society happily and peacefully. Student identity for university students is classified as an individual identity which relates to internal aspects that the others perceive. Social identity is related to interaction in society. The Office of the Higher Education Commission and Thai Qualifications Framework for Higher Education of 2009 set a policy that everyone should learn throughout their lives and build Thai society to become a society of life quality and integration between intelligence, morals, and culture. This is lifelong learning for Thai people to live happily in society.

Graduates are very important to drive the development of the country because the learning system at the university level aims to aid the graduates for enhancing career life, developing themselves with quality and worthiness for society. Thus, providing the learning system to meet with the objective of the educational system at the university level is very crucial and should use a learning system based on practical activity. In the studies of the philosophy of John Dewey, he was named for the experimenter, experience observer, activist and naturalist due to his philosophy that mainly stated about experiences (Dewey, Democracy and Education,1916, p. 7879). He is an American student that has an important role in the educational system in the United States of America and all over the world. He stated that the process of learning for each individual will be achieved successfully must come from working and doing by themselves.

The Rajamangala University of Technology Lanna elaborates on a specific educational system related to Science and Technology which underlying producing hands-on graduates with morality and stability. Graduates can be the prototype of hands-on graduates that are full of morality and reliability which are based on fundamentals of science and technology. Also, creating research that highlights knowledge and innovation, preserving the arts, culture, and environment, creating a good management system that leads to self-reliance which conforms to the National Policy of 2017. This National Policy emphasizes sustainable human development. From reorganizing the educational system in various countries, skills and professionals are the significance for hands-on more than the content in the textbook. UNESCO recommends that students should have 3 skills which are fundamental skill, working skill, and professional skill. If the students have all 3 aforementioned skills, they will be able to adapt, face the challenges and 


\section{International Journal of Social Science and Economic Research}

ISSN: $2455-8834$

Volume:06, Issue:01 "January 2021"

solve the problem during working and in the society (Charoenwongsak,2006) which will lead to high-quality citizens in future society.

Hence, Experience-based Learning is another method that students will be able to learn from their experiences or what they have seen before. They will be able to work by themselves which will lead to finding and learning from experiences. Meanwhile, they can reflect what they have learned as a development for themselves and create their own identity. Experience-based Learning activates the students to think and work through the on-field activity which makes students learn more than what they normally learn inside the classroom. This learning system is related to the Constructivism of John Dewey that emphasizes learning from past experiences to create new learning ideas that suit students and nowadays society.

From the above-mentioned problem, the researcher uses the result of different ways of learning to develop the Lanna Community Based Analysis. This learning system gives significance to students to develop their Management Skills according to Robert L Katz,1974 that includes Technical Skills, Human Skills, and Conceptual Skills. Due to the fast-growing global trend, upto-date society, economics, and culture, students need to develop themselves to sustain their skills for the changing Thai and global society.

\section{Objective}

To generate the conceptual framework of Lanna community-based analysis management skills to hands-on graduates' identity for the community of Rajamangala University of Technology Lanna.

\section{Conceptual Framework}

The conceptual framework of Lanna community-based analysis management skills to hands-on graduates' identity for the community of the Rajamangala University of Technology Lanna which leads the researcher to study the conceptual framework by 


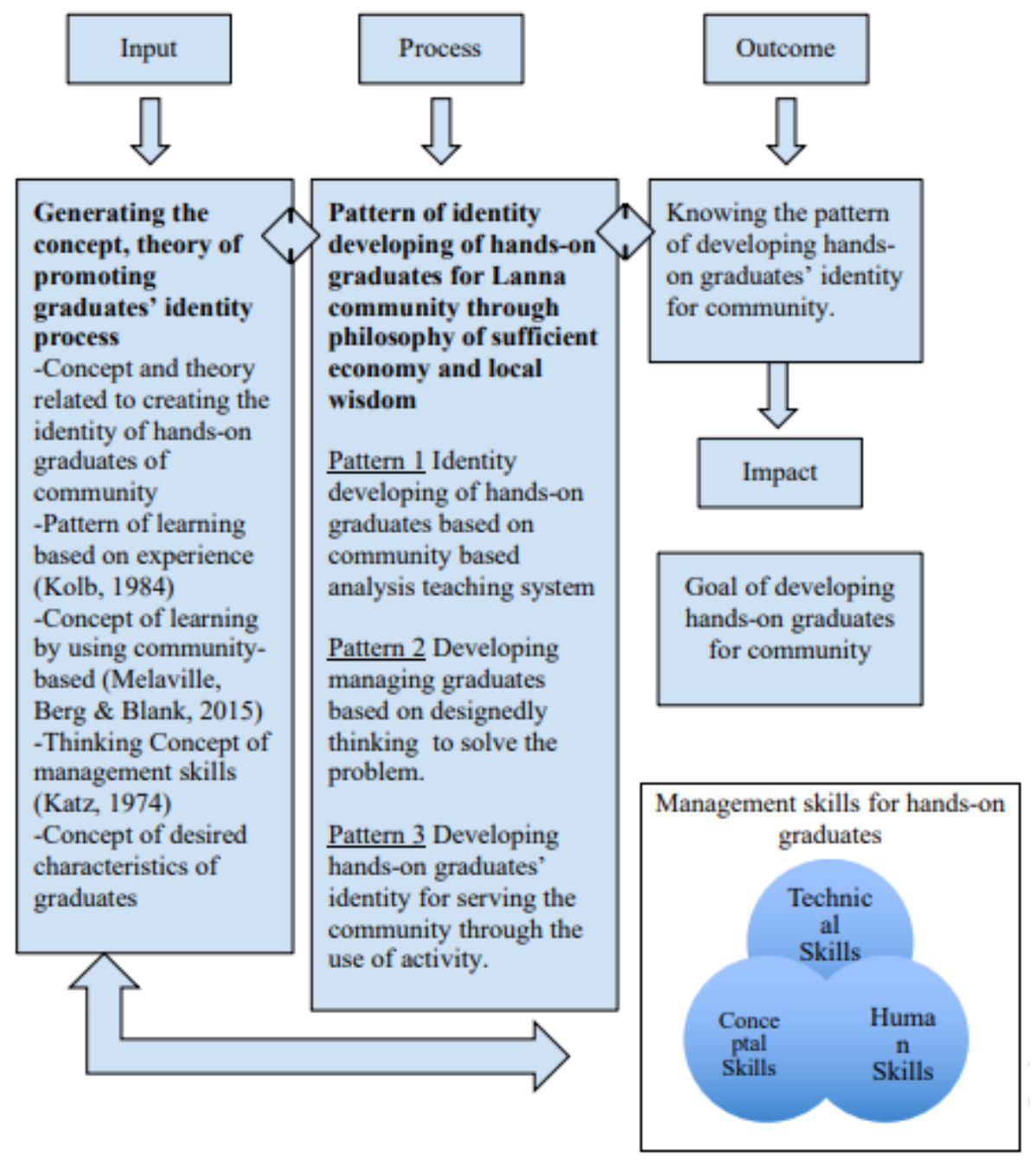

Figure 1 Conceptual Framework of developing hands-on graduates for community

\section{Research process}

Research Scope

1. Scope of contents: Scope of content that researchers specify are

1.1 Study, analyse the ideas about learning from experiences and management skills of hands-on graduates

1.2 Generate the conceptual framework of Lanna community-based analysis to enhance the management skills of hands-on graduates

2. Scope of population 


\section{International Journal of Social Science and Economic Research}

ISSN: $2455-8834$

Volume:06, Issue:01 "January 2021"

The population that we use in this research is the students that registered in this course which are 43 students in total. (Philosophy of sufficiency economy and wisdom of living Semester 1/2562).

\section{Research Result}

The researcher generates the conceptual framework according to the research. Below is the results:

\section{Concept of preparing hands-on graduates of 9 universities within Rajamangala University of Technology connections}

In 1988, your loyal subject is most grateful for Your Majesty's boundless and gracious kindness for vocational students. King Bhumibol Adulyadej, Rama IX, has renamed the Institute of Technology and Vocational Education into Rajamangala Institute of Technology which means the auspicious institute of technology for the king on September 15, 1988. Thus, the university uses this day to be Rajamangala Day.

9 universities within Rajamangala University of Technology connections

Use the word "Hands-on graduates" as a guideline for creating the educational system according to the royal guidance during the graduation ceremony of Rajamangala graduates in 1982. The essential point of the royal speech was "Every graduate in every major has an important role which is being useful, creative and creating prosperity for the country. To get the ball rolling, you must be very determined. "Get the ball rolling" has such a wide meaning which means variously doing something but the most obvious way is to use our hand to work for something. Thus, we use the word "hands-on". Getting the ball rolling on something is depending on our brain or hearts that guide us to do it. Hence, if our heart is not strong enough such as being lazy, weak and hesitant we will not be able to hands-on that work or making that work bad or worst which is exploited ourselves and the others. This is not useful and creative at all.This will create only bad things and faultiness. Hands-on people must always train their hearts as fundamental. Firstly, the heart must be firm, steady and organized. It should not give up on any obstacles and not focus on the easiness. The most important thing is to always be precise, fair and honest. So, this will help you to become a good hands-on graduate. The meaning of good hands-on graduates includes the work that needs to practice both physically and mentally. They always need to work based on their good knowledge, improve themselves, seeking new and current knowledge to create benefits for ourselves and others."

According to the royal guidance of his majesty the King Bhumibol Adulyadej, Rama IX, Rajamangala University of Technology Lanna is one of the nine universities in Rajamangala University of Technology connections that use the royal speech as a guideline for creating education system and curriculum to produce hands-on graduates to work for the society based on the local culture of the upper northern province according to Lanna identity. This based on 


\section{International Journal of Social Science and Economic Research}

ISSN: $2455-8834$

Volume:06, Issue:01 "January 2021"

RMUTL identity which is

$\mathrm{R}$ : Responsibility (Responsible to mission, community, society and country)

$\mathrm{M}$ : Morality (Focusing on moral, goodness)

$\mathrm{U}$ : Unity (Being unite together as one)

$\mathrm{T}$ : Technology (Use science and technology for developing)

L : Learning Society

These are the important keys that drive everyone in the organization to the same goal which is becoming the university of innovation for the community. (Rmutl,2020) .

\section{Identity concept of Thai graduates}

Researchers review the meaning concept of identity and focus on the concept of various thinkers in the Postmodern period which includes understanding the phenomenon in society, accessing the truth of various things and believing in the truth. Identification means specifying the identity which means the process of the person that defines themselves based on things or other persons. Identity is the property of humans or things that is specific and makes that person or thing become highly recognized from the others. (Oxford Dictionary, 2010) However, this meaning is altered due to the new theory in the Postmodernism period.

Identity is the concept that overlaps with many fields of study such as social sciences, sociology and philosophy. Identity is very special because it connects between two sides. After all, on one side, identity connects and relates to society (Apinya Fuengsakul, 2003: 48-50). The root word of identity comes from Latin language which is Idem. Idem means the same ,however, in English, identity has two meanings that have the same meanings and the meaning is unique and different. This is based on the interpretation of relativity and comparing between two persons or objects in different views. (Prasit Leeprecha, 2004: 32-33) Identity does not exist in the object or human and not abruptly set with the object or human but it is created dynamically at all times (Richard Jenkins,1996). Identity is created during the social process and after ideas crystallization, it can be changed depending on the social relativity. (Berger and Luckmann,1967: 173) Identity makes us recognize ourselves who we are, how we build a relationship with others and how we live in this world. It creates the path of the journey for us and tells us who is different from the others. Mostly, identity is created based on the differences that we can see (Kathryn Woodward,1997). An identity is a small unit in sociology that links the attitude toward the person and behaviour of each person according to his/her role (Stryker \& Burke ,2000).

Apinya Fuengsakul (2003) said that there are two types of identity which are Personal Identity and Social Identity. Whilst, Erickson (1968), a psychologist said that building an identity is a lifelong process and humans can change their important characteristics. Erickson chooses to use 


\section{International Journal of Social Science and Economic Research}

ISSN: $2455-8834$

Volume:06, Issue:01 "January 2021"

the word "Identity" instead of personality because this implies the freedom to choose each person. Thus, everyone needs to be responsible for the pathway that they choose in their lives. Identity crisis is the sign that shows that you find yourself. You do not know who you are, feeling not confident in your ability and do not know how to build relationships with other people. Thus, the next step is to choose whether to have an isolated personality or associate the identity with society. Durkheim said that dynamic is the power of ritual which combines with individuals and produces the symbol that represents the identity of society. He emphasises on the power of ritual both cognitive and emotive aspects. Ritual is a language that conveys its meaning through emotion and excitement of people who participate in the holy atmosphere at the ritual.

The key part to think in the modernism period is the philosophy in the enlightenment period in the 18th century. Thus, creating the social theory in this period would be like Grand theory.This theory is seeking international laws to understand and be able to explain human behaviour. Hence, the main thinking process in this period is called Essentialism which believes that nature, society and humans have common properties that are hiding inside deeply and specify the individual behaviour that we have seen. Identity in the new period that shows in sociology theory is that sociology was built into another branch of study in the late 19th century. The main characteristics are proposing the individual vision within the social context of pioneers of this branch of study such as Emile Durkheim. Durkheim believed that naturally, society has a holding force that is above and powerful enough to force individual beliefs or the identity of society to not decrease its value to become conscious of each individual instead. In brief, the identity of a society is not the same as the identity of an individual. Karl Mark emphasis on the importance of specifying the structure instead of an individual. The structure means the structure of the thinking process. In order to understand individual behaviour, we need to look at their habitat and other factors which is the concept of class. The concept of class determines the individual identity and connects the individual with the structure.

Researchers have generated the identity concept and define its meaning by using the concept of the individual identity of Erickson. This will guide the learning system that builds the identity of management for the students which is a lifelong process. Humans can change, develop their identity. Hence, humans can train themselves what they want to be like and always adapt themselves to conform with the situation and time.

\section{The concept of encouraging management identity of hands-on graduate for community}

Researchers study the theory that relates to identity development of hands-on graduates for the community by using Katz's concept (1974) which is correlated with the fast-growing world. As the world changes, human resources should develop and give importance as well. The important factor that gives the organization to become more successful in creating the management skill for the students to transfer the concept of producing hands-on graduates for the community. Thus, 
International Journal of Social Science and Economic Research

ISSN: $2455-8834$

Volume:06, Issue:01 "January 2021"

management identity that graduates should have are

Table 1 Classification of skills

\begin{tabular}{|l|l|l|l|l|l|l|}
\hline No. & Item & No. & Item & \multicolumn{1}{l|}{$\begin{array}{l}\text { No } \\
.\end{array}$} & Item \\
\hline \multicolumn{2}{|c|}{ Technical Skills } & \multicolumn{2}{|c|}{ Human Skills } & \multicolumn{2}{|c|}{ Conceptual Skills } \\
\hline 1 & Change Management & 1 & $\begin{array}{l}\text { Communicatio } \\
\text { n Skills }\end{array}$ & 1 & Strategic Planning \\
\hline 2 & Stress Management & 2 & Organize Skills & 2 & System Skills \\
\hline 3 & $\begin{array}{l}\text { Technological } \\
\text { Management Knowledge }\end{array}$ & 3 & Team Skills & 3 & Time Management \\
\hline 4 & Information Literacy & 4 & $\begin{array}{l}\text { Time } \\
\text { Management } \\
\text { Skills }\end{array}$ & 4 & $\begin{array}{l}\text { Decision Making and } \\
\text { Problem-Solving Skills }\end{array}$ \\
\hline 5 & $\begin{array}{l}\text { Negotiation and Conflict } \\
\text { Management }\end{array}$ & 5 & $\begin{array}{l}\text { Critical } \\
\text { Thinking and } \\
\text { Problem } \\
\text { Solving }\end{array}$ & 5 & $\begin{array}{l}\text { Lanna Technical } \\
\text { Knowledge }\end{array}$ \\
\hline 6 & Risk Management & 6 & Social Skills & 6 & Innovation skills \\
\hline 7 & Crisis Management & 7 & $\begin{array}{l}\text { Leadership and } \\
\text { Responsibility } \\
\text { Skills }\end{array}$ & 7 & Analytical Skills \\
\hline 8 & $\begin{array}{l}\text { Project Management } \\
\text { Social and emotional } \\
\text { competencies to navigate } \\
\text { complex life and work } \\
\text { environments. }\end{array}$ & 8 & $\begin{array}{l}\text { Personal skills } \\
\text { Sross-Cultural } \\
\text { Skills }\end{array}$ & 8 & $\begin{array}{l}\text { The ability to determine } \\
\text { their roles appropriately. }\end{array}$ \\
\hline
\end{tabular}

Robert L. Katz suggests that humans should have 3 important skills which are Technical, Human and Conceptual skills. Technical Skills are the knowledge and performance that you have to organize the activity that involves working and processing processes. Human Skills are the ability to work with other people, trying our best to build teamwork and creating a harmonious 
relationship while working. Conceptual Skill is the ability to analyze the situation to be the thinker and analyzer effectively. Understanding the composition of the works will lead to a better vision and association of the working system. Students need to be able to solve the problem whether it is unexpected or long-term problems. This can be summarized in Diagram 1 below.

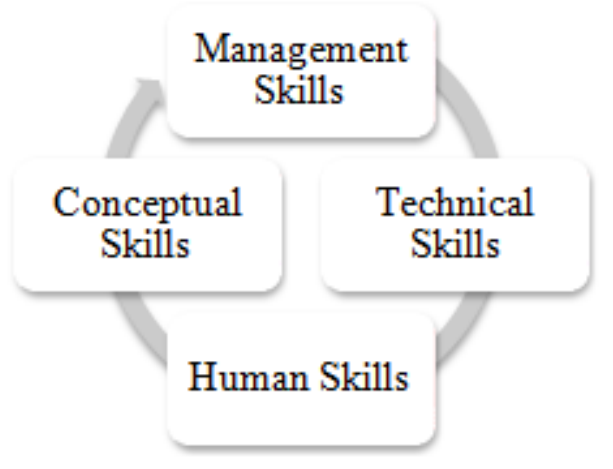

Diagram 1 illustrates the identity management of hands-on graduates for the community. (Katz,1978)

\subsection{Lanna Community Based Analysis Concept}

Researchers generate the theory that relates to the learning system based on the Lanna Community Based Analysis. Thus, researchers found the process of promoting the identity management of creating hands-on graduates for the community. 


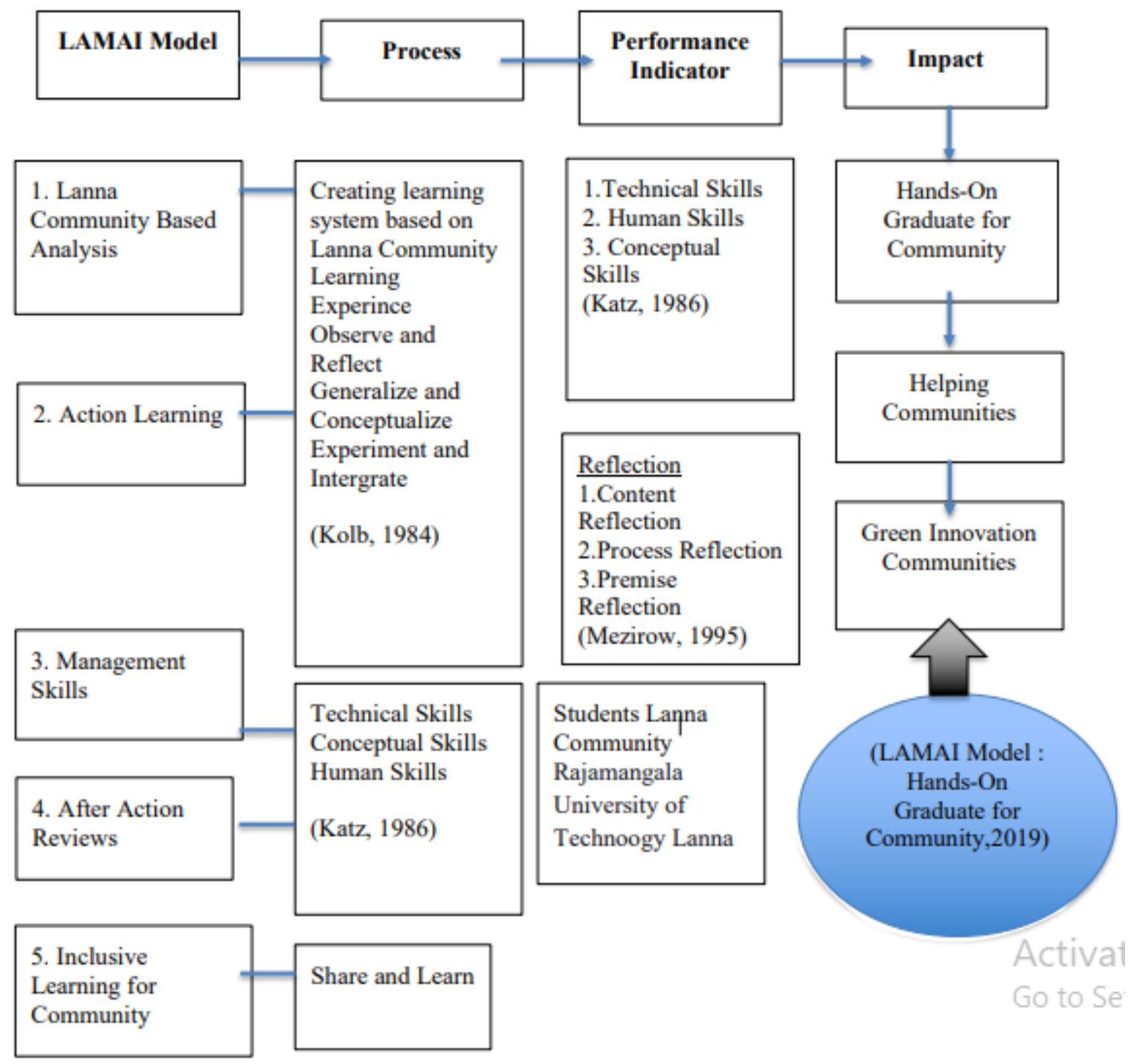

Diagram 2 Process of identity improving for hands-on graduates of community

Using the LAMAI Model to promote the management skills for the hands-on graduate of community involves in 6 steps:

Step 1 Lanna Community Based Analysis (L)

In this step, students will be able to analyze and learn from the Lanna community, so students can achieve the experiences through the hands-on process for constructing the knowledge and realize the importance of the community that contributes to the life-long learning process along with practical skills. The results of this research do not only promote the university to have innovation for society but also, being the example of Community Based Analysis. 


\section{International Journal of Social Science and Economic Research}

ISSN: $2455-8834$

Volume:06, Issue:01 "January 2021"

Step 2 Action Learning (A)

In this step, researchers use the learning system that emphasizes experiences. Kolb (1984), generated the learning process that emphasizes on experiences by starting from the concrete experiences, reflecting and concluding the conceptual thoughts. This learning system highlights the hands-on learning process hence, students will be the ones who generate new knowledge by perceiving the problem, finding the solution and working until the students gain the experience. This knowledge will be useful in real-life for the students thus, students will have the experiences in thinking and working by using the aforementioned concept.

Step 3 Management Skills (M)

Through this step, students will plan by using strategic planning, set the goal and find the solution to achieve that goal. Students should have organized, leading and controlling skills, so they can follow the plan effectively. Besides, interpersonal roles, leadership, resource allocation, negotiation, digital skill, team management, job description, responsibilities, relation-building, conceptual \& decision competency, systemic thinking are the advantages that students should have to be competitive with the others. In addition, associating problem-solving \& decisionmaking skills and performance management skills together would be beneficial as well.

Step 4 After Actions Reviews (A)

Students will recap their experiences, then share and discuss that information with friends and lecturers. After that, students can revise their abilities in designing the products to solve the problem in the Lanna community. Students should also exchange their experiences about Community-Based Analysis and the results of the solution in solving the Lanna community problem.

Step 5 Inclusive Learning for Community (I)

This step is creating the learning environment in the Lanna community by learning together with the Lanna community, university and students through the social environment and community area as a base of thinking and understanding the identity of hands-on graduates for the community.

\section{Conclusion and Discussion}

According to the results of Lanna community-based analysis management skills to hands- on graduates identity for the community of students from the Rajamangala University of Technology Lanna, researchers review the literature, journals and researches about creating the learning system for hands-on graduates' identity of the community. The results can be discussed that in creating the identity for students in this research means the identity of graduates for the community that emphasizes on identity management for the students. Creating the students' 


\section{International Journal of Social Science and Economic Research}

ISSN: $2455-8834$

Volume:06, Issue:01 "January 2021"

identity closely related to the process of learning that comes from the curiosity and training the students to be ready for learning new things to use that knowledge to develop, improve ourselves and also participate in the Lanna community activities. Lairio, Puukari\&Kouvo,(2013: 118) Identity is the characteristics of self-structure that emerge within each individual that could vary over time due to the ability, believes and adaptation. If the good development of self-structure exists then, we will have high self-confidence and know the similarities and differences of ourselves and others. Conversely, if the bad development of self-structure exists then, confusion will emerge and we will rely on outer resources to judge ourselves (Marcia, 1980). Moreover, identity also includes the unique property of each individual that makes us become highly recognize and different from the others. Originally, "Identity" was used to represent the unique characteristics of a person or thing.

Furthermore, creating the identity of students at the university level closely related to managing the learning system and learning environment (Nygaard \& Serrano, 2009: 233). Hence, this can be said that generating the learning process that makes the students learn from community-based which contributes to other factors that the university can create the identity of students successfully. Creating an identity at the university level is very important because it is preparation before working in the future. During working life, those crucial skills that students learn in the university will be very useful and help the students live in society happily.

\section{Suggestions}

\section{Suggestion for the application of research result}

1.1 Every department of education that related to promoting the learning system of hands-on graduates for the community should generate the learning process that helps the students practice management skills. The learning process should aid the students to learn and be able to work in real life, learning to live with other people in society. Also, the learning process should make the students responsible for the society and community, be able to manage their lives in concert with the fast-growing world.

1.2 University has specified the learning policy for the students to achieve the complete identity of humans. The learning process should have coordination between community, university and students. The community also supports and helps to get the most benefits for both students and the community. The learning process should be variety because this will provide the opportunity for local people to participate. The learning process that gathers a lot of students together and also related to the philosophy is very important because each student has their differences and demands thus, it is a responsibility of the education system that needs to serve the needs of students. Every place can be the classroom for learning and the environment should support the students to learn as well. The lecturer must be prepared to meet the students' needs in the 


\section{International Journal of Social Science and Economic Research}

ISSN: $2455-8834$

Volume:06, Issue:01 "January 2021"

education system.

1.3 University should create a learning environment that suitable for students, curriculum and lecturers. Parents and the community can also participate in planning and utilizing the policy to pass the guidelines in developing the learning system of that university to the next generation. The policy planning should start planning from the fundamental policy to the central policy. The lecturers should reflect on the learning development of students every semester to improve the curriculum. This leads to the development of students to become high-quality adults in the future with being self-value and creative for the society.

\section{Suggestions for further research}

From the research results, we found that the teachers should create an assessment related to the current situation and the students learning process. The assessment should reveal the problem, good quality feedback and information that would be beneficial for students to review their learnings. The information provided should provoke the students to improve their learning process and use that information to further expand their ideas, behavior, morality and desired identity. Last but not least, the students can know their pros and cons for improvement thus, teachers should use the positive communication information that makes the students eager to learn and improve themselves throughout their lifetime.

\section{References:}

1. Atkinson, J.D. and Bolt, S. (2010). Using teaching observations to reflect upon and improve teaching practice in higher education. Journal of the Scholarship of Teaching and Learning. $10(3), 1-19$

2. Cavanagh, M., \& Prescott, A. (2010).The Growth of Reflective Practice among Three Beginning Secondary Mathematic teacher. Asia-Pacific Journal of Teacher education. 38 (2), 147-159

3. Chareonwongsak, K. (2006). The Philosopher educator.Bangkok:Success Media. (in Thai)

4. Fuengfoosakul, A. 2003. Identity: Revision on Theories and Concepts. Bangkok: National Research Council of Thailand, Sociology. (In Thai)

5. Glasgo Sinkinson, C. (2011). An Assessment of Peer Coaching to Drive Professional Development and Reflective teaching. Communication in Information Literacy. 5 (1), 9-20.

6. Hand, A.M. \& Bueno D. (2015) Learning in out-of-class experiences; The importance of professional skills. Psychology Learning and Teaching Journal. 14, 62-69.

7. Harris, M. B. (1995) Basic statistics for behavioral science research. Boston: Allyn \& Bacon. 


\section{International Journal of Social Science and Economic Research}

ISSN: $2455-8834$

Volume:06, Issue:01 "January 2021"

8. John Dewey (1916) Democracy and Education.The Macmillan Company.

9. Katz, Danial \& Kahn, Robert L. (1978). Organization and Management :A Systems Approach.2nded.New York:McGraw-Hill Book Company.

10. Kolb, D. A. (1984). Experiential learning : experience as the source of learning and development. Englewood Cliff, New Jersey : Prentice-Hall.

11. Kittiwimonchai,P,.\& Sirisuksilp.S. (2016).Characteristics and Indicators to Become HighPerforming Organization (HPO) for Higher Education Case Study: Khon Kaen Universit, Suranaree J. Soc. Sci, 10. (1), 83-104

12. Kurtts, S., \& Levin, B.(2000). Using peer coaching with pre-service teachers to develop reflective practice and peer support. Teaching Education, 11 (3), 297-31

13. Leeprecha, P. (2004) Cultural Redefinition for Forest Conservation among the Hmong. (In Thai)

14. Ma, J., \& Ren, S. (2011) Reflective Teaching and Professional Development of Young College English Teachers. The Perspective of Constructivism Theory and Practice in Language Studies, 1(2), 153-156

15. Mayhew, M.J., Seifert,T.A., \& other.(2010).Amulti-institutional assessment of moral reasoning development among first-year students. Review of Higher Education 33 (5), 357 390

16. Melaville, A, Berg, A. C. and Blank M. J. (2015, May 20). Community-based learning : Engaging students for success and citizenship. Partnerships/Community. Paper 40. Retrieved on June 15, 2018, from http://digitalcommons.unomaha.edu/slcepartnerships/40

17. Mezirow J. (2000) Learning as transformation: Critical perspectives on a theory in progress. The Jossey-Bass higher and adult education series: ERIC.

18. Pollard, A. (2008) Reflective Teaching. 3rd Ed New York: Continuum. Scales, P (2008). Teaching in the Lifelong Learning Sector. UK: Bell \& Brain, Ltd.

19. Wonsri, P., \& Sutthirat, C. (2019) Resul of learning management with social learning process to enhance mind of public clup students. Journal of Education Naresuan University, 21 (40), 239-253

20. Rotjanalert,N.(2018). A Study on Learning Competencies of Education Students in Silpakorn University. Journal of Education Research 10(10),11-27 